\title{
An institutional framework for designing and monitoring ecosystem-based fisheries management policy experiments
}

\author{
Murray A. Rudd \\ Fisheries \& Oceans Canada \\ Policy \& Economics Branch - Maritimes Region \\ PO Box 1035, 176 Portland Street (6th Floor, Marine House) \\ Dartmouth, Nova Scotia \\ Canada B2Y 4T3 \\ Phone: 902-426-4825 \\ Fax: 902-426-6767 \\ Email: RuddM@dfo-mpo.gc.ca
}

Copyright (C) 2002 by Murray A. Rudd 


\begin{abstract}
Indicator systems are seen as central tools for ecosystem-based fisheries management, helping to steer fisheries towards sustainability by providing timely and useful information to decisionmakers. Without testing hypotheses about the links between policies and outcomes, however, indicator systems may do little more than promote ad hoc policies, prolonging the transition to fisheries sustainability. The Institutional Analysis and Development (IAD) framework is a robust framework that has been used extensively to design policy experiments and empirically test theories and models linking ecological-economic systems, institutions and the sustainability of common pool resource systems. A modified IAD framework is developed that transparently encompasses both pressure-state-response and sustainable livelihood frameworks, thus providing a platform for ecosystem-based fisheries management policy experiment design, monitoring and the communication of complex information on the state of fisheries sustainability. The institutional approach to designing and monitoring fisheries policy experiments facilitates critical examination of important ecological economic issues in fisheries, including the role of fisheries policy compliance on sustainability and how market, government and non-governmental organizations use strategic investments in capital assets and institutions to achieve sustainability. The emphasis on capital keeps attention on the relative returns accruing to investments in different types of capital assets and facilitates the consideration of 'non-traditional' policy responses. The Scotia-Fundy multi-species groundfish fishery is used to illustrate aspects of the modified IAD framework. The framework should, however, be broadly applicable to problems of policy design and monitoring at project- to sector-level for various resources requiring ecosystem-based management.
\end{abstract}

Keywords: Ecosystem-based management; Institutional Analysis and Development; sustainability indicators 


\section{Introduction}

According to the American Fisheries Society, "sustainability of fisheries and other aquatic resources is a state in which these resources, and the ecosystems that support them, are managed in such a way that their long-term viability and productivity are maintained for the benefit of future generations" (Knuth et al., 1999). Achieving sustainability has proven elusive to date, but it is internationally recognized as a primary goal of fisheries management (FAO, 1995; NMFS, 1999; NRC, 1999; Garcia, 2000; Garcia and Staples, 2000; Charles, 2001) and is institutionalized at international (United Nations Convention on the Law of the Sea and Fish Stocks Agreement (UNCLOS); FAO Code of Conduct for Responsible Fisheries), regional (e.g., Commission for the Conservation of Atlantic Tuna) and national levels (e.g., Canada's Ocean Act and USA's Magnuson-Stevens Fishery Conservation and Management Act).

There is a growing consensus that a new ecosystem-based fisheries management paradigm is needed for achieving fisheries sustainability (NRC 1999; Gislason et al. 2000; Weeks and Berkeley, 2000). General principles of ecosystem-based management have been outlined by Christensen et al. (1996) and Mangel et al. (1996) and the need for a precautionary approach to ecosystem-based fisheries management is recognized in Principle 15 of the Rio Declaration (Garcia and Staples, 2000). The precautionary approach is characterized by an explicit recognition of ecological and socio-economic uncertainty and a change in management focus from maximizing resource yield to the maintenance of ecosystem structure and function that provides value by helping humans achieve long-run aspirations. Under ecosystem-based fisheries management, experimental management is needed to build further understanding about complex fishery system processes (Walters, 1997); this goes beyond just implementing better ecological monitoring and ad hoc responses to unexpected management impacts, replacing evolutionary learning by trial and error with directed learning by a process of active policy selection. 
Policy selection is directed by societal goals as ecosystem-based management is outcomeoriented, considering objectives of conservation, economic efficiency and social well-being (Christensen et al., 1996; Mangel et al. 1996; Costanza et al., 1998). Thus, human values, incentives and behaviors need to be broadly considered in ecosystem-based fisheries management. Institutions, the human-crafted rules and norms that infuse social order, shape human incentives and behavior (Ostrom, 1990, 1999a). A variety of institutions (means), however, might be crafted to achieve any particular objectives (ends) envisioned under ecosystem-based fisheries management. Even small-scale, self-governing fisheries use a plethora of rules to govern when and how resources are harvested and used by particular users (Ostrom, 1990; Ostrom et al., 1994) and in more complicated fisheries the rule set may become very complex (e.g., Sinclair et al., 1999). Furthermore, the array of options may vary greatly in costs, making it be necessary to design and monitor ecosystem-based fisheries management policy experiments that strategically test the cost-effectiveness of policy bundles that can help achieve sustainability.

Garcia and Staples (2000) observe that "a framework is necessary and must be developed which shows the various dimensions of the [fishery] system, the factors at work and their relationships, as well as the key criteria for which indicators will need to be established and monitored" (p. 392). A variety of frameworks have been proposed to monitor fisheries sustainability (Garcia and Staples, 2000; Garcia et al., 2000; Sutinen et al., 2000; Charles, 2001), the sustainability of other common pool resources (Prabhu et al., 1999; Campbell et al., 2001), and for broader assessment purposes (Ashley and Carney, 1999; Hammond et al., 1995; Bossell, 1999; OECD, 2000; Smith et al., 2001; UN, 2001; World Bank, 2001). The OECD pressure-state-response (PSR) framework $(\mathrm{OECD}, 2000)$ and variants are process-oriented frameworks that are gaining favor in the fisheries field (Garcia and Staples, 2000). Exogenous driving forces and endogenous anthropogenic impacts exert pressure on the state of the environment; societies respond by 
attempting to mitigate the pressures through management or other means. An alternative structurally-oriented framework, the sustainable livelihood (SL) model (Ashley and Carney, 1999; Bebbington, 1999; Bossell, 1999), is popular in the forestry and agricultural development fields (Prabhu et al., 1999; Campbell et al., 2001). An emphasis in the SL framework is on the role of capital assets (natural, produced or physical, human, social and financial) on sustainability and human welfare.

Under UNCED's Agenda 21 (1992, Chapter 40), indicators of sustainable development must be developed to provide a solid basis for policy decisions. Indicator systems are seen as pragmatic precautionary tools that can help steer fisheries towards sustainability by defining action tasks before scientific knowledge is complete (Caddy, 2002), potentially providing a basis for early warning about threats to sustainability (Garcia and Staples, 2000). The emphasis in both PSR and SL frameworks has been primarily on using indicator systems to provide useful information to decision-makers (Ashley and Carney, 1999; Garcia and Staples, 2000; Garcia et al., 2000); relatively little explicit emphasis has been placed on the role of frameworks in developing policy experiments. Without testing hypotheses about the links between policies and outcomes, however, indicator systems may do little more than promote ad hoc policy responses, prolonging the transition to fisheries sustainability. There is, therefore, a need to use a framework that can be used for both the design and monitoring of fisheries policy experiments.

The Institutional Analysis and Development (IAD) framework (Ostrom, 1990, 1999b) is a robust framework that has been used extensively to design policy experiments and empirically test theories and models linking institutional change and the sustainability of common pool resource (CPR) systems (Schlager, 1990; Oakerson, 1992; Ostrom et al., 1994; Imperial, 1999; SprouleJones, 1999; Yandle, 2001). The strength of the IAD framework is derived from its systematic theoretical focus on the impact of rules and norms on individual incentives in complex 
ecological-economic systems, its empirically-oriented focus on outcomes (including the transaction costs of management) and by its accounting for dynamic system interactions at multiple tiers of analysis (Ostrom, 1999b). To date, however, the IAD framework has not been used to organize indicators of sustainability.

In this paper, I present a modified IAD framework that transparently encompasses both the PSR and SL frameworks, thus providing a platform for ecosystem-based fisheries management policy experiment design, monitoring and communication. There are several potential benefits that are noteworthy when using the IAD framework for ecosystem-based fisheries management. First, compliance with fisheries regulations, which is often difficult to deal with in other frameworks, is handled cleanly as compliance is an aggregated behavioral pattern of individuals responding to economic and social incentives. Second, societal responses to threats to natural (and other) capital are clearly differentiated through the investment choices that various sectors of society (including private, public and collective action organizations) make in response to those threats. Third, the inclusion of social capital (cleaved into community and institutional capacity components) creates opportunities for considering investments in social networks and trust- and norm-building activities as control variables in ecosystem-based fisheries management experiments. Further, the IAD framework is conducive to research and monitoring relating to the transaction cost minimizing balance between government, industry and community organizations in comanaged fisheries. While this paper focuses on fisheries management, drawing on examples from the Canadian Scotia-Fundy multi-species groundfish fishery (Sinclair et al., 1999; DFO, 2000, 2001, 2002; Halliday and O'Boyle, 2001), the modified IAD framework can be applied to other renewable resource systems that utilize ecosystem-based management approaches. 


\section{The Institutional Analysis and Development Framework}

The IAD framework was developed by scholars at the Workshop in Political Theory and Policy Analysis, Indiana University (Ostrom, 1990; Oakerson, 1992; Ostrom et al., 1994) as a multidisciplinary tool to frame policy research on public goods and common pool resources (CPRs) at multiple levels of analysis. It does this by facilitating the organization and analysis of specific policy problems, and by identifying the universal elements that policy researchers need to consider. It was originally used for studies of metropolitan public services (McGinnis, 1999a) and later applied in a wide variety of fields, including the study of governance systems, donorsponsored international development infrastructure projects, and international political order (Ostrom et al., 1993; McGinnis, 1999b). A common theme running through the diverse research is that an institutional framework can be productively applied to the study of public and quasipublic goods that require cooperation if long-term sustainability is to be achieved.

The general elements of the IAD framework are illustrated in Figure 1. When conducting an institutional analysis, the analyst first identifies the 'action arena' or the focus of analysis that is of primary interest. In ecological-economic analyses, a geographically explicit action arena accounts for the behavioral linkage between contextual variables and rules-in-use, on the one hand, and ecological, social and economic outcomes on the other.

$<$ insert Figure 1 about here $>>$

Actors can be viewed as goal-oriented but fallible learners, who have limited resources and cognitive capacity, and function in uncertain environments (Ostrom, 1999a). Institutions are crafted by humans to increase predictability and provide order in uncertain environments, hence facilitating the production of public and quasi-public ecosystem goods and services. Institutions are comprised of formal rules (e.g., property rights, laws) and/or informal prescriptions (e.g., 
norms, taboos) that permit, prohibit or require certain actions or outcomes while specifying the sanctions for breaking rules (Crawford and Ostrom, 1995). The action arena is the primary focus of institutional analyses that seek to predict outcomes of policy experiments on the basis of implicit or explicit models of human behavior.

The contextual variables that frame and constrain the action arena need to be specified; in most IAD analyses, these include variables relating to the physical and material world within which the actors interact, the attributes of community, and the formal rules and informal norms that define the 'rules-in-use'. Given a set of exogenous constraints, actors within the action arena consider the costs and benefits of various behaviors, and act according to their personal preferences and perceived incentives. Their aggregate patterns of interaction (e.g., fishing effort) lead to outcomes (e.g., rent capture, stock depletion) that can be evaluated according to socially relevant criteria (e.g., sustainability, adaptability, efficiency, equity). Outcomes dynamically feed back to both the action arena and to higher levels, potentially causing pressures that will ultimately change the rules-in-use or contextual variables, hence feeding back to change perceived incentives within the action arena.

IAD analyses can also be carried out at these higher levels of decision-making (McGinnis, 1999b). At the collective choice level (Figure 2), analyses focus on how rules regarding resources access and harvesting methods are formulated, rather on the day-to-day operational consequences of those rules. At an even higher constitutional level, analyses address questions of whom is eligible to craft collective choice level rules and how their preferences are aggregated (e.g., committee voting rules). Cultural factors (i.e., relatively stable long-run values and beliefs) shape and influence decisions at all levels.

$<<$ insert Figure 2 about here $>>$ 
Imperial (1999) outlines the utility of the IAD framework specifically for ecosystem-based management, noting that it recognizes the full range of transaction costs associated with policy implementation, draws attention to contextual ecological conditions and constraints, and provides a systematic means of analyzing the structure of institutional arrangements. Transaction costs are particularly important for ecosystem-based management analyses because they tend to rise when jurisdictional complexity rises, when actors are heterogeneous in preferences, or when asymmetries in power or information exist.

\section{Modified IAD Framework for Ecosystem-Based Fisheries Management}

It is useful to recast the IAD framework in terms that are (1) familiar to fisheries scientists and managers, and (2) are useful for developing criteria and indicators for monitoring sustainability. In the following section, the structure and features of a modified IAD framework and its relationship to the PSR and SL frameworks is outlined. Note that a variant of the PSR framework accounts for exogenous driving forces and the impacts of human decisions in a DPSIR (Driving Forces-Pressure-State-Impact-Response) framework (Garcia and Stapleton, 2000). Figure 3 shows the modified IAD framework with five types of capital (including two components of social capital) from the SL framework and incorporating DPSIR terminology.

$<<$ insert Figure 3 about here $>>$

\section{Capital Stocks}

Capital assets are used to transform resources into goods and services that help fulfill human aspirations. All types of capital share two fundamental distinguishing characteristics: each capital investment entails an opportunity cost (savings or consumption foregone) and each permits people to be more productive (Castle, 1998). Capital stocks are used in the SL framework 
(Ashley and Carney, 1999; Bebbington, 1999; Bossell, 1999; Prabhu et al., 1999; Campbell et al., 2001) and, given the historical emphasis of IAD research on the production and allocation of CPRs, a modification of the original IAD framework to specifically include capital assets is reasonable.

Natural capital provides a flow of ecosystem goods or services that humans use to improve their well being. The value of these goods and services derives from direct, indirect and/or non-use functions. The 'strong sustainability' principle proposes that substitutability between natural and human-made capital is limited, implying that relative rates of resource depletion must be less to or equal the natural rate of renewal. This principle is broadly accepted by fisheries managers and is institutionalized under UNCLOS and the FAO Code of Conduct for Responsible Fisheries (Garcia and Staples, 2000).

Physical (= 'human-made', = 'manufactured') capital is the stock of produced assets that people can use over time. It includes equipment, facilities, technology and software devices that are designed to increase the effectiveness or efficiency of the process of transforming resources, including fish, into outputs that contribute to human well being. Physical capital stocks depreciate and require investment to maintain. Human capital is an asset in that it helps people increase their productivity and efficiency in the transformation of resources into goods and service and is, thus, complementary to physical capital. It is now widely recognized that human capital can be developed through investments in the training, education and health of workers (Helliwell, 2001).

The broad complex of social networks, norms, rules and protocols comprise social capital (Ostrom, 1999a; Rudd, 2000; Woolcock and Narayan, 2000; Helliwell, 2001). An increase in social capital reduces the cost of CPR production by increasing the likelihood of successful coordination and collective action. Social capital, in turn, is a function of social interaction and 
structure. At the micro-level of individuals and communities, social capital can serve three functions, as an asset that can be used for either 'bonding', 'bridging' (Woolcock and Narayan 2000) or 'linking' (Woolcock, 2001). Bonding results when strong intra-community ties give kin and communities a sense of identity and common purpose. Bridging results when communities endowed with diverse inter-community ties are in a stronger position to confront problems and take advantage of economic opportunities. Linking refers to the capacity of community members to gain sustained access to decision-makers in private and government organizations. Thus, community capacity is a function of internal norms and networks but there is also an interactive element relating to the broader institutional infrastructure and formal governance organizations. At the macro-level of public sector organizations, State capacity can be defined by criteria that include transparency and accountability, support for well-defined property rights via legislation and legal infrastructure, and the availability of sufficient financial and human resources to fulfill ecosystem-based fisheries management mandates.

Financial capital is special because it is generated by the production process (i.e., resource rent capture) and can be re-invested in any other type of capital. Financial capital generated by fishery resource rents accrue to the owners or users (i.e., property rights holders) of the resource. This could be either government or private interests, depending on the licensing, taxation and property rights regimes. For example, there has been a recent move in Canadian fisheries to management cost recovery by passing on certain costs (e.g., observer monitoring) to industry and increasing license fees (Sinclair et al., 1999; DFO, 2002). Rent dissipation - caused by conflicts, overcapitalization, or rent seeking - decreases the potential financial resources available to society, thus imposing costs on society as a whole and reducing future options for maintaining or improving societal well being. A central concern of ecosystem-based fisheries management is the development of appropriate governance regimes and institutions that constrain short-term opportunism and maintain natural capital that increases long-run total economic value. 


\section{Rules-in-Use}

The institutions (rules-in-use) that influence actor incentives and behavior include both social norms and formal rules (i.e., regulations, laws, bundles of rights). A norm is "a pattern of behavior that is customary, expected and self-enforcing. Everyone conforms, everyone expects others to conform, and everyone has good reason to conform because conforming is in each person's best interest when everyone else plans to conform" (Young, 1996: 105). Formal rules specify actions or outcomes that are permitted, prohibited or required, and prescribe formal sanctions for rule violation (Crawford and Ostrom, 1995).

Regulatory approaches are widely used in fisheries and take on a number of different forms generally aimed at controlling fishing effort and/or increasing the age at which fish become vulnerable to fishing. If a threat of detection and punishment is not credible, individual behavior in unlikely to change significantly even with formal rules in place. Halliday and Pinhorn (in press) note that there has been a history of poor compliance in the Scotia-Fundy groundfish fishery. In particular, the issue of discarding at sea or modifying trawl gear (Pinhorn and Halliday, 2001) has potentially serious effects because stock assessments, which depend on reliable estimates of fish stock size and age composition, can lead to the implementation of inappropriate ecosystem-based fisheries management policies. As Pinhorn and Halliday (2001) observe, "it would, of course, be particularly helpful if fishermen, who have been such a driving force for more stringent regulation of size at first capture, could be convinced to respect those regulations that are in place" (p. 37). That is to say, there is a need for congruence between social norms and rules, otherwise the cost of regulation can escalate drastically and resource rents be dissipated.

Pure regulatory approaches to achieve fisheries sustainability are today seen as untenable and, as a result, there has been an increasing move to rights-based fisheries, where property rights and 
market incentives are used in attempts to achieve sustainability (e.g., Yandle, 2001). The American Fisheries Society foresees a larger role for industry involvement in ecosystem-based fisheries management: "By 2004, we expect that...business and industry will participate in ecosystem-based management because ecosystems are "owned" privately as well as publicly, and environmental agencies will move away from control-driven to incentive-driven regulatory schemes." (Knuth et al., 1999).

Property rights are a type of institution, composed of bundles of rules that (1) limit access to a resource and (2) limit the amount, technology, timing used to withdraw diverse resource units from the system (Ostrom, 2000). Operational level rules governing timing, technology, purpose of use, and quantity are devised by those holding higher level collective choice rights of management and exclusion. Schlager and Ostrom (1992) developed a matrix of property rights and categories of rights holders. 'Claimants' hold rights of resource access and withdrawal, and additional collective choice rights to participate in the management process, including making decisions concerning resource harvest limits and production technologies; many fisheries 'quasi property rights' for many fisheries are at this level. At the next higher level of property rights, 'proprietors' hold additional rights to determine who may access and harvest fish. At the highest level, 'owners' - who may be individuals, corporations, communal groups, or government - have property rights that permit the transfer or sale of their rights subject to specific conditions.

Property rights in the Scotia-Fundy groundfish fishery have been evolving continually since the early-1980s (Sinclair et al., 1999; DFO, 2002). Large boats (> 100-ft) in the offshore fishery were initially granted Enterprise Allocation (EA) quotas in 1984. These quotas have some inter-fleet transferability clauses and have helped the EA fleet to become essentially self-regulating. Quotas were implemented for the 65 - to $100-\mathrm{ft}$ mobile gear fleet in 1988. Both the mobile gear and EA 
fleet have substantial input in management decisions, although the ultimate responsibility for management still rests with the Department of Fisheries and Oceans (DFO).

In Scotia-Fundy, the < 45-ft inshore fixed gear fishery was under competitive quota until 1995 (Sinclair et al., 1999). In 1996, an experimental community quota system was implemented (and since institutionalized) where overall quotas for fixed gear were initially divided into seven shares based largely on recent catch history. Each community was then free to use a range of allocation and management measures with their member fishers (i.e., they hold proprietor level property rights). There are currently about 3,000 licenses managed under this system, a reduction of 30\% since 1992 (DFO, 2002); of these only about one-third are active as many inshore fishers derive most of their income from licenses they hold in other fisheries (primarily lobster).

\section{Action Arena}

Policy experiments link policy options to hypothesized outcomes by using explicit or implicit models of human choice within the action arena. The action arena is described by two sets of variables, one related to the characteristics and capabilities of relevant actors, and the other related to the structures that shape the incentives that actors perceive for various behaviors. Actors can be characterized by four sets of variables in an institutional analysis (Ostrom, 1990; Ostrom et al., 1994): the resources they bring to a situation; the way that they internally value alternate actions and outcomes; the knowledge and information that they acquire and possess; and the mechanisms by which actors select particular actions. In general, actors can be thought of as goal-oriented but fallible learners who respond to economic incentives. Which actors are considered relevant in policy experiments and monitoring is situation-specific. Those people or groups that directly use the resource for consumptive or non-consumptive purposes, governance organizations that manage the resource, and actors that monitor compliance should be considered. 
The action situation considers the set of actors, their positions, the set of allowable actions and potential outcomes for these actions, the level of control that actors have over their choices, the information available, and the costs and benefits of alternative actions and outcomes.

\section{Pattern of Interaction and Impacts}

Actors make choices based on their own preferences (or mandates, in the case of government agencies), the costs and benefits that they assign to alternative actions and outcomes, and strategic considerations (i.e., expectations of the behavior of others). These individual choices lead to the patterns of interaction relevant for ecosystem-based fisheries management. Under the IAD framework, behavioral patterns of interaction are distinguished from impacts or outcomes. Patterns of interaction result directly from actor behavior and, in an operational level fisheries analysis, three main patterns will be of interest: fishing effort; fishing location; and rule compliance. These patterns, in turn, lead to impacts such as total landings, bycatch, net income and other more complex derived outcomes (e.g., technical efficiency).

Holland (2001), for instance, examines the problem of accounting for the effects of marine reserves on fishers' decisions about site choice and fishing effort. Reserves in productive fishing grounds will displace fishers and can have direct and indirect effects on inter-related fisheries as the focus of fishing effort shifts to new grounds and/or alternative species. Holland argues that the spatial displacement aspects of marine reserve policy decisions have not been adequately taken into account to date and that experimental reserves be established and monitored. Thus, patterns of interaction - site choice and effort level - should be of prime interest in ecosystem-based fisheries management marine reserve experiments.

Policy experiments can have important, and sometimes unanticipated, impacts on fishing effort. In the Scotia-Fundy groundfish fishery, licensing policy during the 1970s and 1980s combined 
with technological advances generated substantial over-capacity in the inshore fixed gear fishery (Sinclair et al., 1999). The implementation of community quotas was originally driven by a desire to transfer management responsibility to fishers rather than being a capacity reduction program per se. Prior to community quotas, all fishers could fish until the global quota was reached. Under community quotas, however, some fishers are closed down quickly while others are distributing their quota through the entire year. The result of devolution has been that some license holders have been squeezed out of the industry, resulting in an unanticipated reduction in groundfish fishing effort. The reduction in effort (a pattern of interaction) has, however, led to increased social tensions (an impact) as the community quota decision making process has been very divisive in some regions (Sinclair et al., 1999).

Compliance with formal rules and regulations deserves special attention in ecosystem-based fisheries management. If there are strong incentives for fishers to cheat, then the likelihood of achieving fisheries sustainability can be severely compromised. The degree and type of monitoring, in combination with the types of penalties for contravening rules, influence the likelihood of cheating. That is, the expected cost of rule violation is a function of both the likelihood of being detected and sanctioned, and the severity of the sanction.

Compliance with established rules has been problem in the Scotia-Fundy groundfish fishery (Sinclair et al., 1999; Halliday and Pinhorn, in press). Sinclair et al. (1999) identify several reasons, one of which is that fines in the 1980s and 1990s were not an effective deterrent for rulebreaking. An experimental administrative sanction system was developed and the penalties for particular infractions were defined in conjunction with industry, who have been very supportive of harsher penalties. Under the modernized Fisheries Act, an independent third-party tribunal administers sanctions. Fishers, however, still utilize a variety of creative ways to skirt rules and capture undersize groundfish (Pinhorn and Halliday, 2001). Compliance is far from perfect 
because fishers know full well that the expected costs of being (1) caught, (2) convicted and (3) strongly sanctioned are often less than the economic benefits derived from illegal behavior.

Impacts need to be defined in terms of relevant evaluative criteria. There are a vast array of possible objectives and indicators of fisheries outcomes and sustainability (Garcia and Staples, 2000; Sutinen et al., 2000; Jamieson et al., 2001). Impacts themselves do not necessarily pose threats to capital stocks; only when the use of ecological goods or services exceeds their rates of renewal does the impact become a pressure. It is also important to understand that not all pressures on capital stocks are endogenous but that exogenous variables (driving forces) also exert pressure on capital stocks (e.g., demographic, environmental or technological change). Macroeconomic market forces are particularly important for analyzing operational level ecosystem-based fisheries management situations because of the speed at which market prices, interest rates and other key variables change, and due to the importance of market price and input cost variables in influencing day-to-day fishing decisions at the operational level.

Some 2,000 of 3,000 of the < 45-ft inshore fixed gear Scotia-Fundy groundfish license holders also hold lobster licenses from which they derive most of their income (DFO, 2002). Lobster landings stayed relatively stable during most of the 1990s and increased substantially over the last five years. Rrices have increased dramatically as well, so most inshore fishers have had more than sufficient income to compensate for declines in groundfish landings. Lobster, a luxury product destined for export markets, is subject to swings in landing price due to a number of macroeconomic factors. Falling demand in export markets or an appreciation of the Canadian relative to the U.S.A. dollar could combine to have serious impacts on the relative returns from lobster and groundfish landings. A wholesale switch from lobster back to groundfish fishing could test the community quota management system as there is still substantial latent capacity in 
the inshore fleet (Sinclair et al., 1999; DFO, 2002) and could create a variety of indirect pressure on financial, social and natural capital assets.

\section{Evaluative Criteria}

The choice of evaluative criteria reflects the vision and objectives of actors within the fishery as well as broader societal interests; ecosystem-based fisheries management should therefore be broadly participatory in nature (Costanza et al., 1998; Garcia and Staples, 2000).

Three broad categories - conservation, economic and social performance - are salient for classification of ecosystem-based fisheries management impacts. In general, conservation criteria consider whether ecological impacts are sufficient to cause deterioration of the stock of natural capital and its ability to provide flows of key goods (e.g., fish) or services (e.g. insurance against declines in resilience). Economic criteria broadly relate to resource rent capture and economic efficiency, accounting for both wealth generation and the transaction costs of management (i.e., reaching agreements, monitoring, enforcement and the costs of ex post opportunism). Social criteria generally focus on equity, either in terms of ensuring that benefits accrue to those that have limited financial means or that those who bear the costs of conservation are the people that benefit most from increases in natural capital. Other public policy analyses have used evaluative criteria of institutional adaptability, conformance with general social norms and values, and bureaucratic accountability or transparency (e.g., Ostrom et al., 1993).

Adaptability is an evaluative criterion that deserves special attention in ecosystem-based fisheries management. When considering institutional adaptability, Sproule-Jones (1999) notes that different actors with different bundles of resource access rights incur different transaction costs. The lower the transaction costs, the more adaptable actors will be and, thus, more willing and able to experiment and innovate in ecosystem-based fisheries management policy experiments. 
Wilson (2002) argues that matching ecological and institutional scale in complex adaptive fisheries systems is the central element needed to ensure adaptability for ecosystem-based fisheries management. Management should focus on maintaining long-run system stability while the production of ecological goods and services cycle within normal bounds, thus allowing resource users to recognize resource abundance patterns and maintain sufficient flexibility to adjust to those cycles. Hierarchical but overlapping governance organizations ('polycentric systems') are known to be effective for producing a number of types of public and quasi-public goods and services (McGinnis, 1999a, 1999b).

\section{Investment Responses}

When capital assets, and hence the productive capacity of humans to fulfill aspirations, are threatened, society can respond in a number of ways. All responses, however, can fundamentally be viewed as investment decisions by market, collective choice or public organizations. Achieving societal objectives implies that certain levels or combinations of capital need to be developed and/or maintained. This, in turn, may require investment or disinvestment in the various types of capital.

Investments by the market and public sectors in manufactured capital falls within the realm of traditional economic theory. Likewise, investments in human capital are now widely recognized to lead to increases in productivity and are important for market and public sector organizations alike (Barro, 2001). Direct investments in natural capital are possible, although often problematic due to our limited understanding of ecosystem dynamics (e.g., cod stock enhancement - Svåsand et al., 2000).

Avrim Lazar, a senior bureaucrat with Human Resources Development Canada, believes that policy makers widely accept that social capital is as important as human capital for economic 
growth and development (Lazar, 2001). He notes, however, that policy advisors are 'totally confused' about (1) how and where to target social investments and (2) how to know what actually works. As a result, "there is a tendency across almost all governments to base the allocation of expenditure on the current immediate needs of people and not on whether or not the expenditure will change the basic conditions giving rise to these needs. In other words, spending is not oriented enough towards investment expenditures" (Lazar, 2001: 5).

Using the IAD framework, it is in fact possible to categorize many societal responses to various pressures into one or more of five broad categories of social capital investment. These include direct investments in community capacity (by increasing structural and/or cognitive social capital) or public sector governance capacity. In addition, investments can be made in institutions at the operational, collective choice and constitutional levels by (1) increasing the level of monitoring and/or enforcement of existing rules, (2) changing the formal rules governing the fishery, or (3) changing the rule-making process itself. Some examples from the Scotia-Fundy region illustrate possibilities.

Community capacity in the groundfish industry has been increased as a result of a number of initiatives. Communication was broadened by increasing industry representation and consultation via fleet-specific Conservation Harvesting Plans and the adoption of Management Boards in the fixed gear sector (DFO, 2002). Science personnel have increased their participation on commercial fishing trips, which has led to increasing trust between fishers and scientists (and broader acceptance of DFO surveys as ecological indicators of groundfish abundance). The new channels of communication also led to the formation of the Fishermen and Scientists Research Society (Sinclair et al., 1999), building bridging and linking social capital in the groundfish industry. At the same time, the Government of Canada is investing substantially to increase DFO's fisheries governance capacity (DFO, 2000) by enhancing communications within and 
between departments ('horizontality' initiatives), building core capacity (by investments in infrastructure and technology), and improving organizational effectiveness. Investments by the collective action sector also play a role in Scotia-Fundy. The Pew Foundation, for example, has allocated substantial funds for marine-related efforts this year (Malakoff, 2002) and some of that funding is being channeled, via local Pew Fellows, to community capacity building in rural fishing and aboriginal communities.

The institutions that influence fisher incentives and behavior can be modified in a number of ways. Investments in better monitoring and enforcement can be made at relatively low cost although enforcement costs can escalate rapidly and become prohibitively expensive if local norms are not congruent with formal rules (Ostrom, 1990). Thus, investments in rule monitoring and enforcement are important for successful resource management, but are not likely sufficient for long-run sustainability. In a multi-species fishery such as the Scotia-Fundy groundfish fishery (19 primary species are landed by the commercial fishery) and where on-board observer coverage is low ( $1 \%$ to $20 \%$ for $<65-\mathrm{ft}$ mobile gear fleet - DFO, 2002), the likelihood of detection of discarding is relatively low. Increasing the sophistication of monitoring through statistical comparisons of landings with shore-based sampling (Allard and Chouinard, 1997) is one method that may alter fishers economic incentives and induce increased compliance with discarding regulations.

Another response is to change the formal rules governing behaviors or outcomes that are required, prohibited or permitted by law. Because changing rules is a higher-level process, possibly involving protracted negotiations amongst those with collective action level rights, societal investments aimed at changing the formal rules-in-use will be more expensive than simply increasing monitoring and enforcement (in the short-term - there is an opportunity cost for long-term returns). Similarly, returns from investments in norm-seeding activities by government, 
NGOs or other 'norm entrepreneurs' may be effective under certain circumstances (Sunstein, 1996). The evolution of the Scotia-Fundy community quota system for the $<45$-ft fixed gear fleet provides an example of a fundamental change in the types of rules-in-use used to manage inshore groundfish fishing (Sinclair et al., 1999). Responsibilities for the choice of rules to manage regional resource access and allocation were devolved to resource users, subject to some broad government policy guidelines. Different communities adopted different resource allocation rule sets as a result, potentially presenting an opportunity to develop formal rules that closely coincide with local norms within the groundfish fleet.

Some institutions can lead to outcomes that do not meet broad societal goals and objectives but that do provide economic benefits to powerful vested interests. When there in on-going tension between certain decision makers or interest groups and society as a whole, there is likely to be increasing calls for political changes about how those involved in the rule setting process are chosen and how preferences are articulated. Hence, operational level rules, such as property rights, can be indirectly subject to wider societal processes of adaptation in which stakeholders articulate and aggregate their preferences (Sproule-Jones, 1999). Rules about the articulation of stakeholder interests are those that refer to selecting and representing stakeholders for the governance process. Aggregation rules deal with the transformation of diverse stakeholder interests into actions that yield outcomes and often specify the timing or frequency of meetings and technical rules about voting needed to resolve conflicts. Constitutional level change is more expensive again relative to lower level changes that change rules or simply devote more resources to enforcement.

In Canada, the constitutional-level process of settling aboriginal land claims has been long and expensive. Using the IAD framework, the costs of constitutional level change - negotiations, legal fees, court proceedings, etc. - can be seen as an investment in high-level rules about who is 
eligible to make lower-level rules about resource harvesting and allocation. The commitment of both aboriginal and public sector organizations to establishing new and inclusive governance systems is strong despite the long-term costs of the process. Subject to conservation requirements, aboriginal rights to fish for food, social and ceremonial purposes already take precedence over other uses of the resource (DFO, 2001). The Supreme Court of Canada's ruling in the Marshall case has, in addition, had a profound impact on the groundfish management rules in ScotiaFundy. The Marshall decision has led to the adoption of policies that increase aboriginal peoples access to, and capacity to function within, the commercial groundfish fishery (DFO, 2002). These long-run constitutional investments help Canadians achieve broad societal objectives of social equity.

\section{Conclusions}

Successful implementation of ecosystem-based fisheries management policies requires that managers consider conservation, economic and social objectives in transdisciplinary policy experiments. There is a need for an analytical framework that be used to both identify and design policy experiments that will guide adaptive ecosystem-based fisheries management and monitor the status of fisheries sustainability.

A number of frameworks have been proposed for use as sustainable development reference systems. The SL framework has been used widely for agricultural development and forestry systems, and the PSR framework is popular for fisheries applications. The IAD framework encompasses both the structurally-oriented SL framework and the process-oriented PSR framework and has a number of features that make it well suited for complex marine fisheries. It was developed as a tool to analyze the production and allocation of diverse public and quasipublic goods in situations ranging from fine-scale irrigation systems to the global-scale 
institutions for the 'production' of peace and security. As a result, it has been used with a variety of different theoretical and modeling approaches, and has a strong empirical orientation necessary for experimental ecosystem-based fisheries management. The IAD framework offers several potential advantages compared to the PSR and SL frameworks as a platform for monitoring the sustainability of complex fishery systems.

Using the IAD framework, compliance is a pattern of interaction that results from the aggregate effects of individual actors reacting according to incentives that are a function of personal preferences, ecological-economic contextual variables, and the norms and formal rules that comprise institutions. Ecosystem-based fisheries management experiments can alter institutions by changing laws, regulations or policies, or alter the perceived costs and benefits of fishers by changing the level of monitoring effort and/or severity of sanctions.

Incorporating capital stock concepts into the IAD framework is important because investments in capital stocks by various actors (government, private, non-governmental) can be viewed as explicit responses designed to achieve an ecosystem-based fisheries management objective. Financial resources are always scarce (i.e., individuals, corporations and resource managers all face budget constraints) and a variety of investment options may be available to help people improve their well being. Financial capital might be invested in habitat rehabilitation (natural capital) that increases the sustainable flow of fish from the ecosystem, in skills development programs for young fishers (human capital), in research that improves fishing technology (physical capital), in meetings that allows fishers to share ideas and build networks (social capital), in enforcement, or in political processes meant to change existing institutions. The benefit-cost ratio of the different investments may, however, be vastly different. Generally, a policy is worthwhile and should be pursued if the discounted benefits of a particular policy exceed its discounted costs and priority should be given to projects and programs that maximize 
social welfare, thus enhancing overall economic efficiency. One important role for policy experiments is to generate information about the relative returns from different types of investments.

By explicitly accounting for collective choice level choices about rule selection and constitutional level choices regarding participation in rule-making decisions, the IAD framework systematically expands the types of responses that managers should consider in ecosystem-based fisheries management policy experiments. These responses include investing in social capital at micro- or macro-levels (i.e., community or government capacity) or investments in changing the set of formal or rules or the rules regarding the rule-making process itself.

In conclusion, the IAD framework is a useful tool for considering an entire spectrum of impacts and outcomes, including the effects of devolution of governance and the creation of increasingly complete property rights (e.g., Yandle, 2001). It is flexible, pragmatic and has a history as a base for rigorous empirical applications. Because it encompasses both PRS and SL frameworks, indicators already in use can be readily adapted and incorporated into IAD-based indicator systems. These features will be crucial if ecosystem-based fisheries management policies are to be successfully developed, tested and implemented in support of sustainable fisheries governance. 


\section{Literature Cited}

Allard, J., Chouinard, G.A., 1997. A strategy to detect fish discarding by combining onboard and onshore sampling. Canadian Journal of Fisheries and Aquatic Sciences 54, 2955-2963.

Ashley, C., Carney, D., 1999. Sustainable livelihoods: lessons from early experience. Department for International Development, London.

Barro, R.J., 2001. Education and economic growth. In: Helliwell, J.F. (Ed.), The Contribution of Human and Social Capital to Sustained Economic Growth and Well-Being: International Symposium Report. Human Resources Development Canada (HRDC) and Organisation for Economic Co-operation and Development (OECD), Hull, Quebec, pp. 13-41.

Bebbington, A., 1999. Capitals and capabilities: a framework for analyzing peasant viability, rural livelihoods and poverty. World Development 27, 2021-2044.

Bossel, H., 1999. Indicators for sustainable development: theory, method, applications. International Institute for Sustainable Development, Winnipeg, Manitoba.

Caddy, J.F., 2002. Limit reference points, traffic lights, and holistic approaches to fisheries management with minimal stock assessment input. Fisheries Research 56, 133-137.

Campbell, B., Sayer, J.A., Frost, P., Vermeulen, S., Ruiz Pérez, M., Cunningham, A., Prabhu, R., 2001. Assessing the performance of natural resource systems. Conservation Ecology 5, 22 [online URL: http://www.consecol.org/vol15/iss2/art22].

Castle, E.N., 1998. A conceptual framework for the study of rural places. American Journal of Agricultural Economics 80, 621-631. 
Charles, A.T., 2001. Sustainable Fishery Systems. Blackwell Science, Oxford. 384 pp.

Christensen, N.L., Bartuska, A.M., Brown, J.H., Carpenter, S., D'Antonio, C., Francis, R., Franklin, J.F., MacMahon, J.A., Noss, R.F., Parsons, D.J., Peterson, C.H., Turner, M.G., Woodsmansee, R.G., 1996. The report of the Ecological Society of America Committee on the Scientific Basis for Ecosystem Management. Ecological Applications 6, 665-691.

Costanza, R., Andrade, F., Antunes, P., van den Belt, M., Boersma, D., Coesch, D.F., Catarino, F., Hanna, S., Limburg, K., Low, B.S., Molitor, M., Pereira, J. G., Rayner, S., Santos, R., Wilson, J.A., Young, M., 1998. Principles of sustainable governance of the oceans. Science 281, 198-199.

Crawford, S.E.S., Ostrom, E., 1995. A grammar of institutions. American Political Science Review 89, 582-600.

DFO (Department of Fisheries and Oceans), 2000. Strategic plan: moving forward with confidence and credibility. Fisheries and Oceans Canada, Ottawa.

DFO (Department of Fisheries and Oceans), 2001. The management of fisheries on Canada's Atlantic Coast: a discussion document on policy direction and principles. Fisheries and Oceans Canada, Atlantic Fisheries Policy Review, Ottawa.

DFO (Department of Fisheries and Oceans), 2002. Groundfish management plan, Scotia-Fundy Fisheries Maritime Region: April 1, 2002 - March 31, 2007. Fisheries and Oceans Canada, Dartmouth, Nova Scotia.

FAO (Food and Agriculture Organization), 1995. Code of conduct for responsible fisheries. Food and Agriculture Organization of the United Nations, Rome. 
Garcia, S.M., 2000. The FAO definition of sustainable development and the Code of Conduct for Responsible Fisheries: an analysis of the related principles, criteria and indicators. Marine and Freshwater Research 51, 535-541.

Garcia, S.M., Staples, D.J., 2000. Sustainability reference systems and indicators for responsible marine capture fisheries: a review of concepts and elements for a set of guidelines. Marine and Freshwater Research 51, 385-426.

Garcia, S.M., Staples, D.J., Chesson, J., 2000. The FAO guidelines for the development and use of indicators for sustainable development of marine capture fisheries and an Australian example of their application. Ocean \& Coastal Management 43, 537-556.

Gislason, H., Sinclair, M., Sainsbury, K., O'Boyle, R., 2000. Symposium overview: incorporating ecosystem objectives within fisheries management. ICES Journal of Marine Science 57, 468-475.

Halliday, R.G., O'Boyle, R.N., 2001. Proceedings of the Fisheries Management Studies Working Group, 25-29 June 2007. CSAS Rep. No. 2001/022. Fisheries and Oceans Canada, Dartmouth, Nova Scotia.

Halliday, R.G., Pinhorn, A.T., 2002. A review of the scientific and technical basis for policies on the capture of small fish in North Atlantic groundfish fisheries. Fisheries Research 57, 211-222.

Hammond, A., Adriaanse, A., Rodenburg, E., Bryant, D., Woodward, R., 1995. Environmental indicators: a systematic approach to measuring and reporting on environmental policy performance in the context of sustainable development. World Resources Institute, Washington, D.C. 
Helliwell, J.F. (Ed.), 2001. The Contribution of Human and Social Capital to Sustained Economic Growth and Well-Being: International Symposium Report. Human Resources Development Canada (HRDC) and Organisation for Economic Co-operation and Development (OECD), Hull, Quebec, 509 pp.

Holland, D., 2001. Integrating marine protected areas into dynamic spatial models of fish and fishermen. In: Sumaila, U.R., Alder, J. (Eds.), Economics of Marine Protected Areas, Fisheries Centre Research Report 9(8), UBC Fisheries Centre, Vancouver, pp. 93-98.

Imperial, M.T., 1999. Institutional analysis and ecosystem-based management: the Institutional Analysis and Development framework. Environmental Management 24, 449-465.

Jamieson, G., O'Boyle, R.N., Arbour, J., Cobb, D., Courtenay, S., Gregory, R., Levings, C., Munro, J., Perry, I., Vandermeulen, H., 2001. Proceedings of the National Workshop on Objectives and Indicators for Ecosystem-Based Management. CSAS Rep. No. 2001/09. Fisheries and Oceans Canada, Ottawa.

Knuth, B.A., Birely, L., Burger, C., Claussen, J., DiStefano, R., Franzin, W., Habron, G., MartinDowns, D., Miller, D., Pereira, D., Van Den Avyle, M., Brouha, P., 1999. The Strategic Plan of the American Fisheries Society, 1999-2004. Fisheries 24, 14-24.

Lazar, A., 2001. A Canadian policy perspective on investment in human and social capital. In: Helliwell, J.F. (Ed.), The Contribution of Human and Social Capital to Sustained Economic Growth and Well-Being: International Symposium Report. Human Resources Development Canada (HRDC) and Organisation for Economic Co-operation and Development (OECD), Hull, Quebec, pp. 3-6. 
Malakoff, D., 2002. Going to the edge to protect the sea. Science 296, 458-461.

Mangel, M., Talbot, L.M., Meffe, G.K., Agardy, M.T., Alverson, D.L., Barlow, J., Botkin, D.B., Budowski, G., Clark, T., Cooke, J., Crozier, R.H., Dayton, P.K., Elder, D.L., Fowler, C.W., Funtowicz, S., Giske, J., Hofman, R.J., Holt, S.J., Kellert, S.R., Kimball, L.A., Ludwig, D., Magnusson, K., Malayang III, B.S., Mann, C., Norse, E.A., Northridge, S.P., Perrin, W.F., Perrings, C., Peterman, R.M., Rabb, G.B., Regier, H.A., Reynolds III, J.E., Sherman, K., Sissenwine, M.P., Smith, T.D., Starfield, A., Taylor, R.J., Tillman, M.F., Toft, C., Twiss Jr., J.R., Wilen, J., Young, T.P., 1996. Principles for the conservation of wild living resources. Ecological Applications 6, 338-362.

McGinnis, M.D. (Ed.), 1999a. Polycentricity and Local Public Economies: Readings from the Workshop in Political Theory and Policy Analysis. University of Michigan Press, Ann Arbor, Michigan, $424 \mathrm{pp}$.

McGinnis, M.D. (Ed.), 1999b. Polycentric Governance and Development: Readings from the Workshop in Political Theory and Policy Analysis. University of Michigan Press, Ann Arbor, Michigan, 448 pp.

NMFS (National Marine Fisheries Service), 1999. Ecosystem-based fishery management. A report to Congress by the Ecosystems Principles Advisory Panel. U.S. Department of Commerce, Silver Spring, MD.

NRC (National Research Council), 1999. Sustaining Marine Fisheries. National Academy Press, Washington D.C., 184 pp. 
Oakerson, R., 1992. Analyzing the commons: a framework. In: Bromley, D.W. (Ed.), Making the Commons Work: Theory, Practice, and Policy. Institute for Contemporary Studies, San Francisco, pp. 41-59.

OECD (Organization for Economic Co-operation and Development), 2000. Frameworks to Measure Sustainable Development: An OECD Expert Workshop. Organization for Economic Cooperation and Development, Paris, 168 pp.

Ostrom, E., 1990. Governing the Commons: The Evolution of Collective Action. Cambridge University Press, Cambridge, U.K., 280 pp.

Ostrom, E., 1999a. Coping with Tragedies of the Commons. Annual Review of Political Science 2, 493-535.

Ostrom, E., 1999b. Institutional rational choice: an assessment of the IAD framework. In: Sabatier, P. (Ed.), Theories of the Policy Process. Westview Press, Boulder, Colorado, pp. 35-71.

Ostrom, E., 2000. Private and common property rights. In Bouchaert, B., de Geest, G. (Eds.), Encyclopedia of Law and Economics, Volume 2. Edward Elgar, Cheltenham, U.K., pp. 332-379.

Ostrom, E., Gardner, R., Walker, J., 1994. Rules, Games, and Common-Pool Resources. University of Michigan Press, Ann Arbor, 369 pp.

Ostrom, E., Schroeder, L., Wynne, S., 1993. Institutional Incentives and Sustainable Development. Westview Press, Boulder, Colorado, 264 pp.

Pinhorn, A.T., Halliday, R.G., 2001. The regulation of exploitation pattern in North Atlantic groundfish stocks. Fisheries Research 53, 25-37. 
Prabhu, R., Colfer, C.J. P., Dudley, R.G., 1999. Guidelines for developing, testing and selecting indicators for sustainable forest management: a C \& I developer's reference. Rep. No. 1., CIFOR (Center for International Forestry Research), Bogor, Indonesia.

Rudd, M.A., 2000. Live long and prosper: collective action, social capital and social vision. Ecological Economics 34, 131-144.

Schlager, E., 1990. Model specification and policy analysis: the governance of coastal fisheries. Ph.D. dissertation, Department of Political Science, Indiana University, Bloomington, Indiana.

Schlager, E., Ostrom, E., 1992. Property-rights regimes and natural resources: a conceptual analysis. Land Economics 68, 249-262.

Sinclair, M., O'Boyle, R.N., Burke, D.L., Peacock, F.G., 1999. Groundfish management in transition within the Scotia-Fundy area of Canada. ICES Journal of Marine Science 56, 10141023.

Smith, R., Simard, C., Sharpe, A., 2001. A proposed approach to environment and sustainable development indicators based on capital. The National Round Table on the Environment and the Economy's Environment and Sustainable Development Indicators Initiative, Ottawa.

Sproule-Jones, M., 1999. Restoring the Great Lakes: institutional analysis and design. Coastal Management 27, 291-316.

Sunstein, C., 1996. Social norms and social roles. Columbia Law Review 96, 903-967. 
Sutinen, J.G., 2000. A framework for monitoring and assessing socioeconomics and governance of large marine ecosystems. Rep. No. NMFS-NE-158, U.S. Department of Commerce, NOAA, NMFS Northeast Region Northeast Fisheries Science Center, Woods Hole.

Svåsand, T., Kristiansen, T.S., Pedersen, T., Salvanes, A.G.V., Engelsen, R., Nævdal, G., Nødtvedt, M., 2000. The enhancement of cod stocks. Fish and Fisheries 1, 173-205.

UN (United Nations), 2001. Indicators of Sustainable Development: Guidelines and Methodologies. United Nations Department of Economic and Social Affairs, Division for Sustainable Development, New York, 310 pp.

Walters, C.J., 1997. Challenges in adaptive management of riparian and coastal ecosystems. Conservation Ecology 1, 1 [online at www.consecol.org/vol1/iss2/art1].

Weeks, H., Berkeley, S., 2000. Uncertainty and precautionary management of marine fisheries: can the old methods fit the new mandates? Fisheries 25(12), 6-14.

Wilson, J.A., 2002. Scientific uncertainty, complex systems, and the design of common pool institutions. In: Ostrom, E., Dietz, T., Dolsak, N., Stern, P.C., Stonich, S., Weber, E.U. (Eds.), The Drama of the Commons. National Academy Press, Washington, D.C., pp. 327-360.

Woolcock, M., 2001. The place of social capital in understanding social and economic outcomes. In: Helliwell, J.F., (Ed.), The Contribution of Human and Social Capital to Sustained Economic Growth and Well-Being: International Symposium Report. Human Resources Development Canada (HRDC) and Organisation for Economic Co-operation and Development (OECD), Hull, Quebec, pp. 65-88. 
Woolcock, M., Narayan, D., 2000. Social capital: implications for development theory, research and policy. The World Bank Research Observer 15, 225-249.

World Bank, 2001. Expanding the Measure of Wealth: Indicators of Environmentally Sustainable Development. World Bank, Environment Department, Washington, D.C., 110 pp.

Yandle, T., 2001. Market-based natural resource management: an institutional analysis of individual tradable quotas in New Zealand's commercial fisheries. Ph.D. dissertation, Department of Political Science and School of Public and Environmental Affairs, Indiana University, Bloomington, Indiana.

Young, H.P., 1996. The economics of convention. Journal of Economic Perspectives 10, 105-122. 


\section{Captions for Figures:}

Figure 1 - General Elements of the Institutional Analysis and Development (IAD) Framework (modified from Ostrom et al., 1994)

Figure 2 - Multiple Levels of Institutional Analysis

Figure 3 - Modified Institutional Analysis and Development (IAD) Framework 


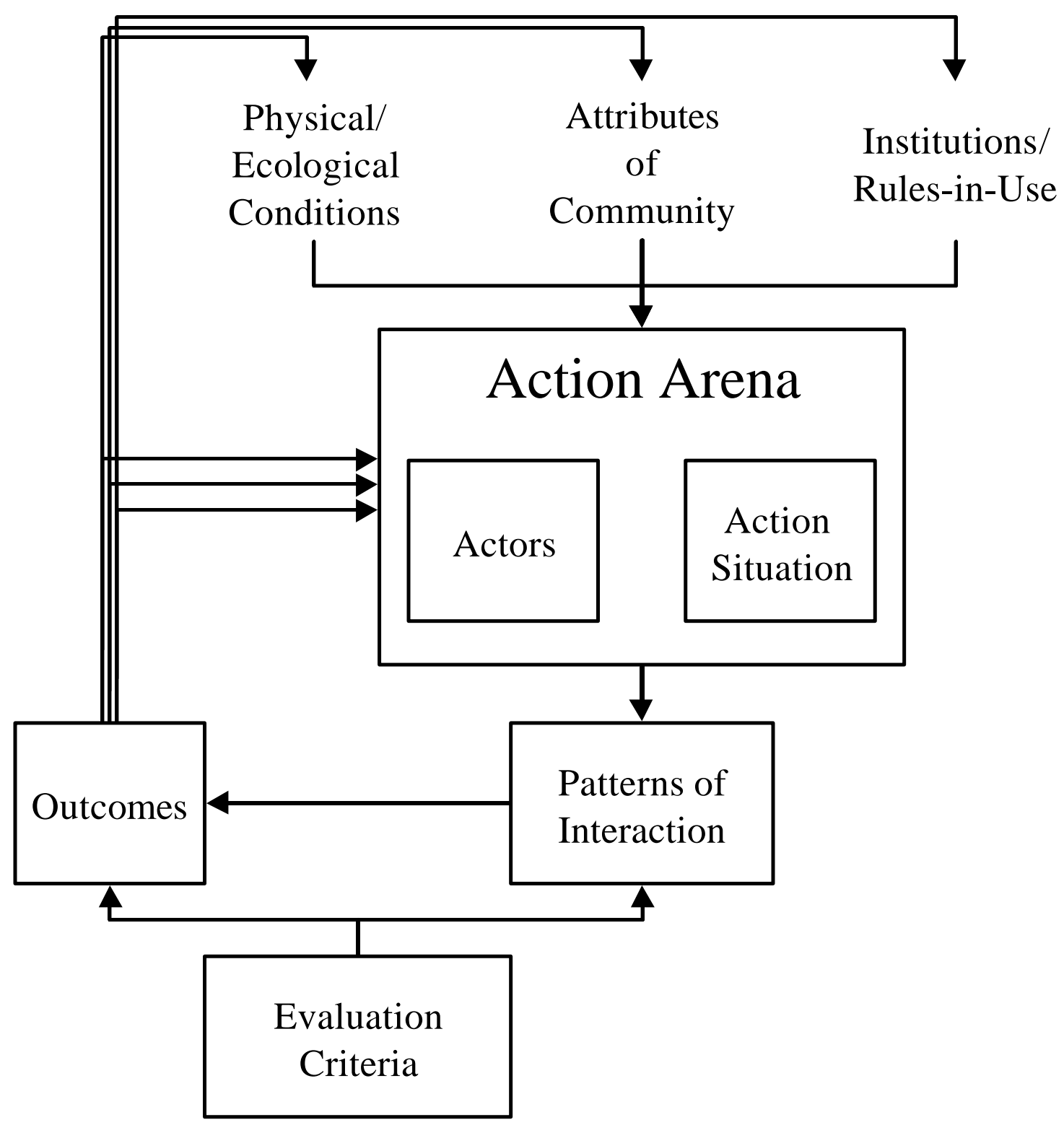

Figure 1 


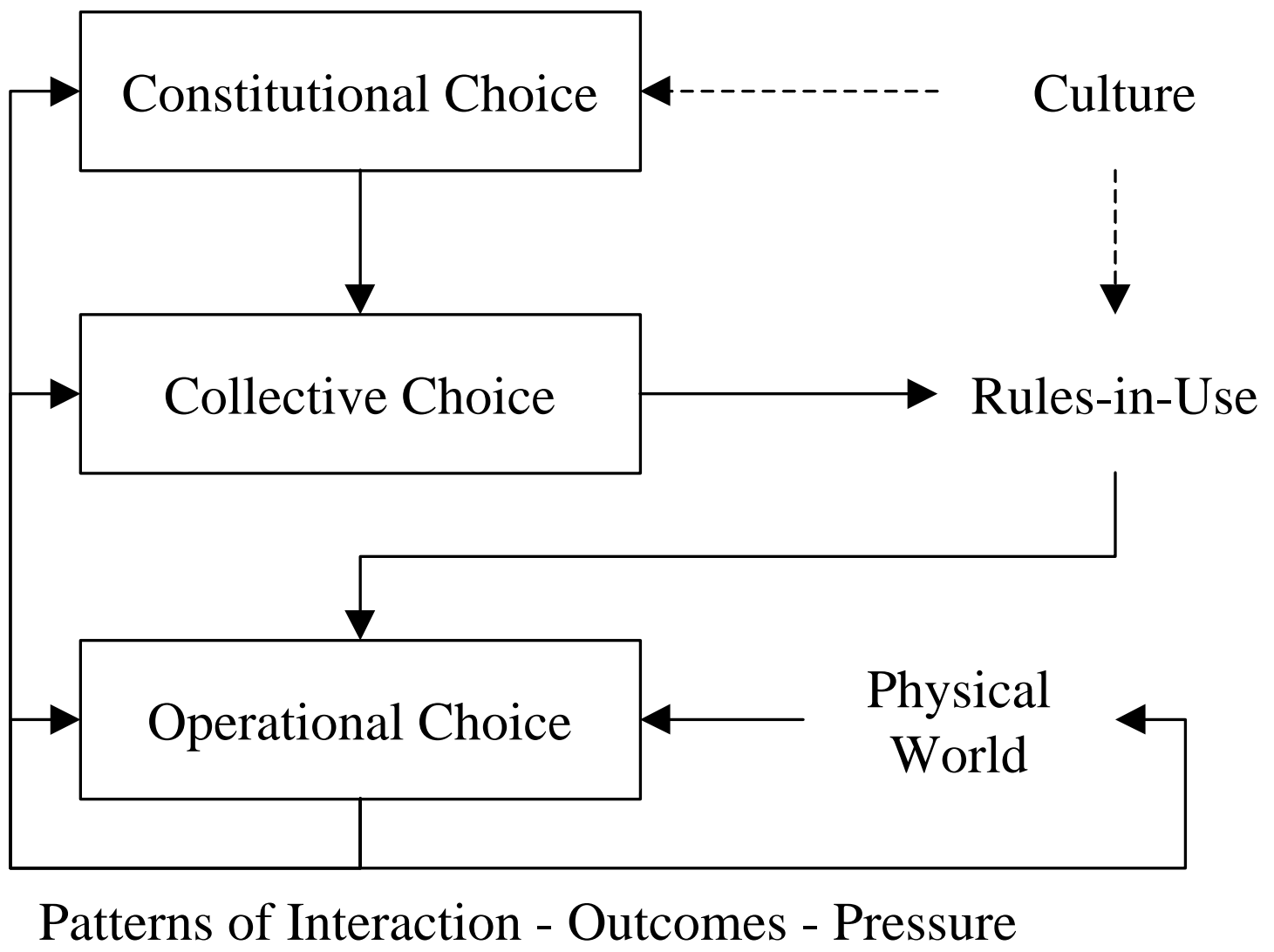

Figure 2 


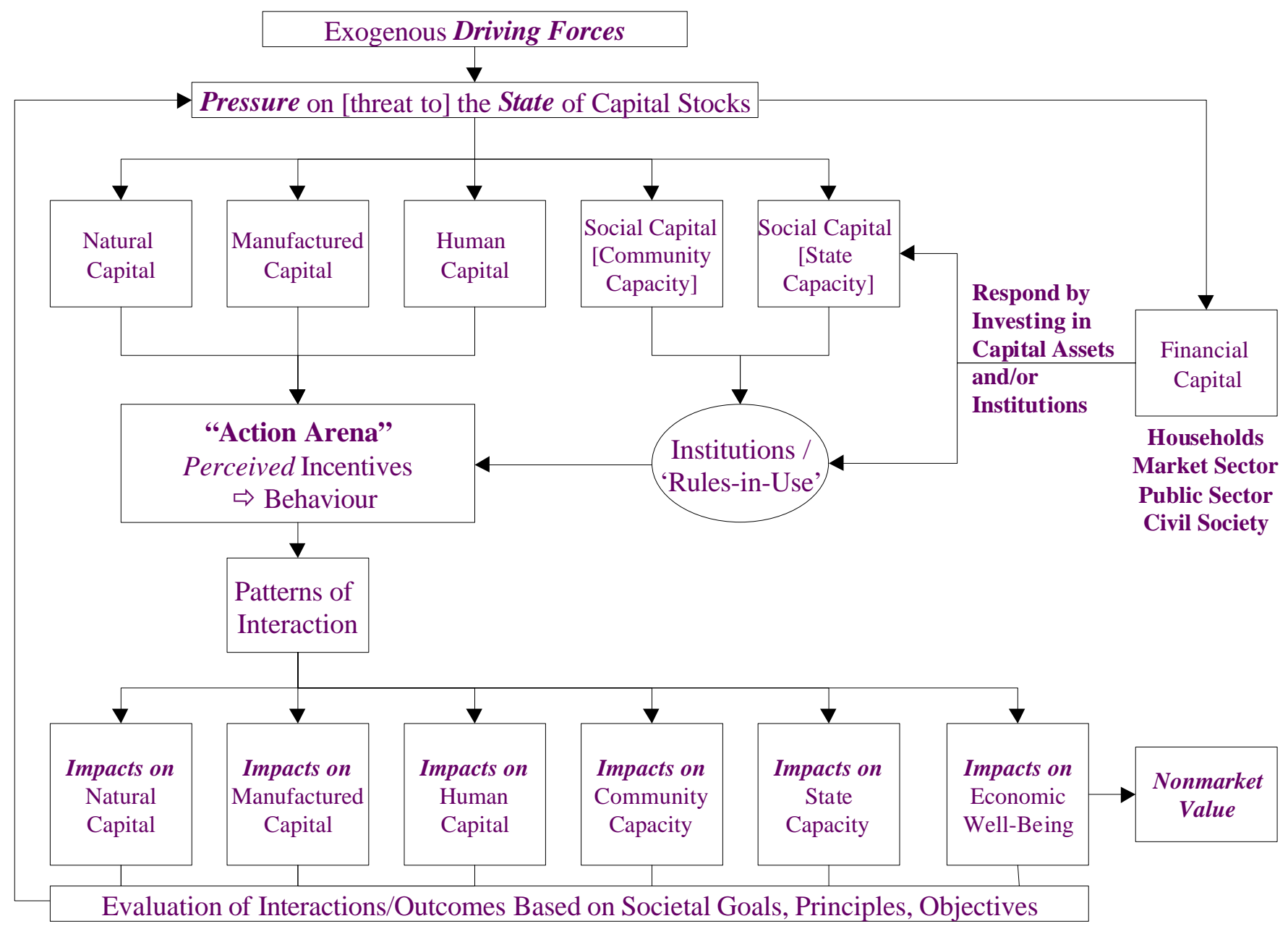

Figure 3 